\title{
Variations Regularity of Soil Nitrate Nitrogen in Hebei Piedmont Plain
}

\author{
Huiyan Gao* and Luhua Yang
}

College of Civil \& Rural Construction, Agricultural University of Hebei, Baoding, Hebei, 071001, P.R. China

\begin{abstract}
Field experiment was carried out to study on the spatial and temporal distribution of soil nitrate nitrogen at Ranzhuang water resources experiment station in Hebei piedmont plain from 2011 to 2012. The results show that nitrate nitrogen content varies in sinusoidal curve at shallow tilth soil and shows in "W" shape at deep soil profile during the wheat-maize rotation period. Nitrate nitrogen is mainly accumulated in $0 \sim 100 \mathrm{~cm}$ soil and the maximum value occur at reviving stage in the wheat growth period. In the maize growth period, the distribution of nitrate nitrogen is double peak curve in $0 \sim 500 \mathrm{~cm}$ soil profile. The maximum peak emerges at $150 \sim 260 \mathrm{~cm}$, the peak of soil nitrate content is between $36.7 \sim 106.36 \mathrm{mg} / \mathrm{kg}$. In $0 \sim 500 \mathrm{~cm}$ soil layers, the cumulative amount of nitrate nitrogen is $1430.56 \sim 5126.05 \mathrm{~kg} / \mathrm{hm}^{2}$. The amount of nitrate nitrogen leaching is $1294.13 \mathrm{~kg} / \mathrm{hm}^{2}$, which is $52.29 \%$ of the total amount of annual fertilization. It is scientific and technical groundwork to improve the utilization efficiency of nitrogen fertilizer and protect groundwater environment.
\end{abstract}

Keywords: Deep transport, field experiment, nitrate nitrogen, piedmont plain.

\section{INTRODUCTION}

Hebei plain, one of China's major grain-growing areas, is located in the southeastern of Hebei Province. In order to increase production, Farmers excessively apply nitrogen fertilizer. According to the survey, the average amount of nitrogenous fertilizer is over $400 \mathrm{~kg} / \mathrm{hm}^{2}$, especially, some high-yielding fields are over nitrogen $500 \mathrm{~kg} / \mathrm{hm}^{2}[1,2]$, which exceeds three times the national average amount of fertilizer applied. After nitrogenous fertilizer into the soil, one part is absorbed by the root of crop; the part of nitrogen fertilizer retains in soil and the other parts leave crop and soil systems through volatilization or leaching [3]. In drought area, Nitrification is extremely strong, and therefore nitrate is the main form of residual inorganic nitrogen in soil. Nitrate has negatively charged itself, which cannot easily be adsorbed by soil and easily migrate down with soil water, and become potential contamination source of groundwater.

Before the 1970s, nitrate nitrogen content is ranged from 0.47 to $10.0 \mathrm{mg} / \mathrm{L}$ in Hebei plain, which close to background values. The average content of nitrate nitrogen is respectively $54.9 \mathrm{mg} / \mathrm{L}$ and $56.2 \mathrm{mg} / \mathrm{L}$ in groundwater in Shijiazhuang area in 2000 and 2005[3]. Since the 1980s, due to large-scale exploitation of groundwater, the groundwater table has the downtrend and the burial depth gradually increases. The average burial depth of groundwater is $36.43 \mathrm{~m}$ in Shijiazhuang city in 2011. he depth of vadose zone becomes thicker, which changes the ratio of surface runoff and recharge of phreatic water, impacts on the accumulation of nitrate in soil and leaching process, and then has a significant impact on the groundwater environment. At present, it is the main research on nitrate accumulation and leaching in root soil layer [4-16]. However, it is less study in deep soil [17-19]. Field experiment was performed at Ranzhuang water resources experiment station which is representative in terrain, soil texture, soil fertility and etc. for Hebei plain. Soil moisture and nitrate nitrogen was dynamic measured in wheat-maize rotation area. The spatial and temporal distribution of soil moisture and nitrate nitrogen was analyzed in traditional cropping pattern. It is scientific and technical groundwork to improve the utilization efficiency of nitrogen fertilizer and protect groundwater environment.

\section{MATERIALS AND METHODS}

\subsection{Experiment Field}

The field experiment was conducted at Ranzhuang water resources experiment station, which is located in Taihang Mountain piedmont plains. It belongs to Semi-humid continental monsoon climate. Annual average temperature is $12.1^{\circ} \mathrm{C}$ and annual average rainfall is $500 \mathrm{~mm}$, which concentrates in summer (from June to September). Annual average evaporation is $974.8 \mathrm{~mm}$ (E-601). Quaternary loose rock is thicker and sandy loam is dominant in vadose zone, of which contains more clay particle in $40 \sim 100 \mathrm{~cm}$. Winter wheat and summer maize are the chief crops. The burial depth of groundwater is about $24 \mathrm{~m}$.

\subsection{Experiment Scheme}

Soil moisture and nitrate nitrogen were measured from 2011 to 2012 in wheat-maize rotation area. The methods of irrigation and fertilization are the same of local farmersconventional irrigation and fertilization. Sowing and harvest date of wheat is respectively October 7 and June 10, and maize is June 12 and September 28. When sowing wheat, compound fertilizer is applied in experiment field, of which total nutrient is above $52 \%$, and nitrogen content is equal to 
$18 \%$. After turning green, ammonium bicarbonate is top dressing. When sowing maize, compound fertilizer is applied in filed. Annual amount of fertilizer is $2475 \mathrm{~kg} /\left(\mathrm{hm}^{2} \mathrm{a}\right)$, which is equivalent to pure nitrogen $445.5 \mathrm{~kg} /\left(\mathrm{hm}^{2}\right.$.a). Irrigation methods are border irrigation and irrigation times is 5, among of them, 4 in wheat growth period and 1 in maize growth period. Irrigation quota is $6075 \mathrm{~m}^{3} / \mathrm{hm}^{2}$. Measured depth is $500 \mathrm{~cm}$ and interval is ranged from 15 to $30 \mathrm{~cm}$, which is $15 \mathrm{~cm}$ in crop root zone. With increasing depth, interval becomes larger. Rainfall and ground water table is monitored at the same time. Precipitation is showed in Fig. (1) during experiment period.

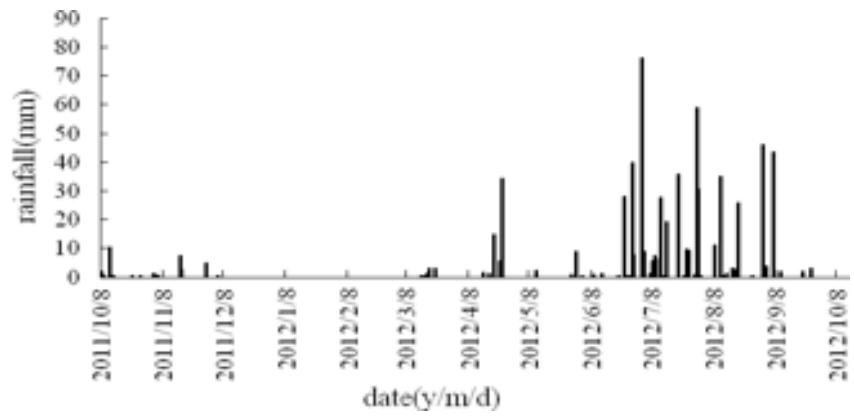

Fig. (1). Precipitation during the growth season of wheat-maize rotation in 2012.

\subsection{Determination Methods}

Soil moisture is determined by drying method-take earth by Luoyang shovel, weigh aluminum box and fresh soil, put them into the oven, bake $105^{\circ} \mathrm{C}$. for $12 \mathrm{~h}$, remove the soil sample, weigh aluminum case and the dry soil, and calculate soil moisture; nitrate is measured by PXSJ-226 ion meterweigh $50 \mathrm{~g}$ fresh soil, add $100 \mathrm{ml}$ of deionized water, shake at the oscillator $1 \mathrm{~h}$, stay the suspension for still 10 15minutes, take $50 \mathrm{ml}$ of the supernatant after filtration of filter paper, add sodium dihydrogen phosphate $0.78 \mathrm{~g}$, and measure the concentration of nitrate after being fully mixed. The data of winter wheat and summer maize cultivation, irrigation, fertilizer and other agricultural activities is dynamically monitored by tracking method; daily precipitation is obtained from meteorological stations near the experiment field; the groundwater table is observed by conventional methods.

\section{RESULTS AND DISCUSSION}

The results of soil moisture and nitrate nitrogen were shown in Figs. $(\mathbf{2}, \mathbf{3})$. X, Y and $\mathrm{Z}$ axis represent respectively date, soil depth and soil moisture or nitrate nitrogen concentration. The experimental date was from November 19, 2011 to November 9, 2012.

\subsection{Distribution of Soil Moisture}

Fig. (2) shows that the soil moisture varies from $21.23 \%$ to $41.67 \%$ ( accounting for a percentage of the soil volume, the same below) in $0 \sim 500 \mathrm{~cm}$ soil layer. The minimum soil moisture is above $70 \%$ of field capacity, and the maximum soil moisture reaches saturated water content. Two peak zones occur respectively at $40 \sim 100 \mathrm{~cm}$ and $300 \sim 400 \mathrm{~cm}$ in soil profile and the maximum value are $36.59 \%$ and $41.67 \%$. It includes smaller particles and larger porosity at the upper peak zone, so soil moisture is higher. The lower peak zone results from excessive irrigation water and precipitation infiltration. Soil moisture near to field capacity between two peak zones and tends to be stable below $400 \mathrm{~cm}$ soil layer.

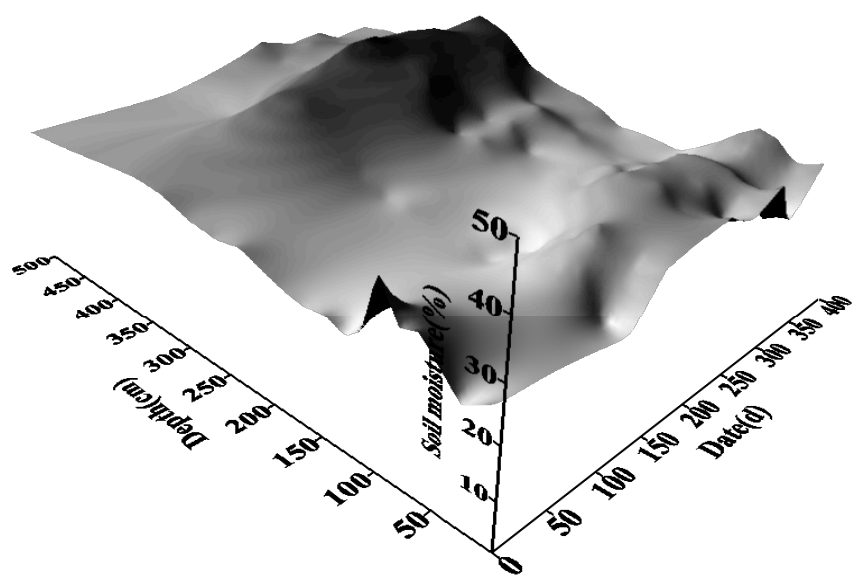

Fig. (2). Distribution of soil moisture in planting area.

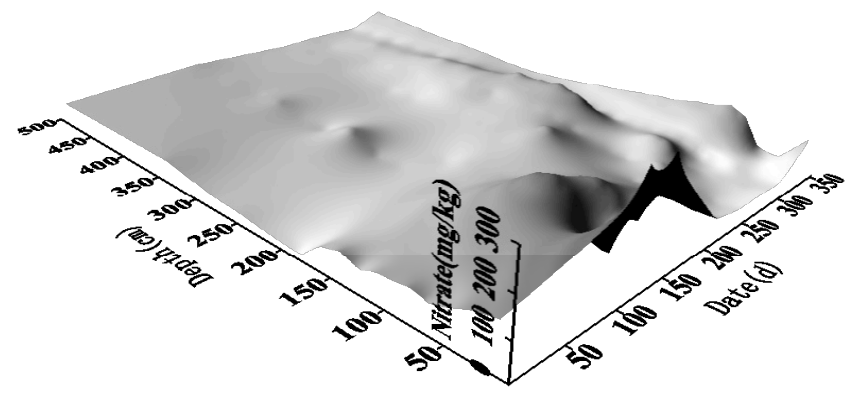

Fig. (3). Distribution of soil nitrate nitrogen in planting area.

\subsection{Distribution of Nitrate Nitrogen}

Nitrate nitrogen is mainly accumulated in the $0 \sim 100 \mathrm{~cm}$ depth soil in the wheat growth period shown in Fig. (3). It forms a peak and the maximum value is $280.39 \mathrm{mg} / \mathrm{kg}$. Unreasonable fertilization and low precipitation are reasons for causing these phenomena. Since vadose zone is thicker in Piedmont area, the distribution of nitrate present different characteristic in topsoil and deep soil, the following are analyzed.

\subsubsection{Distribution of Topsoil Nitrate}

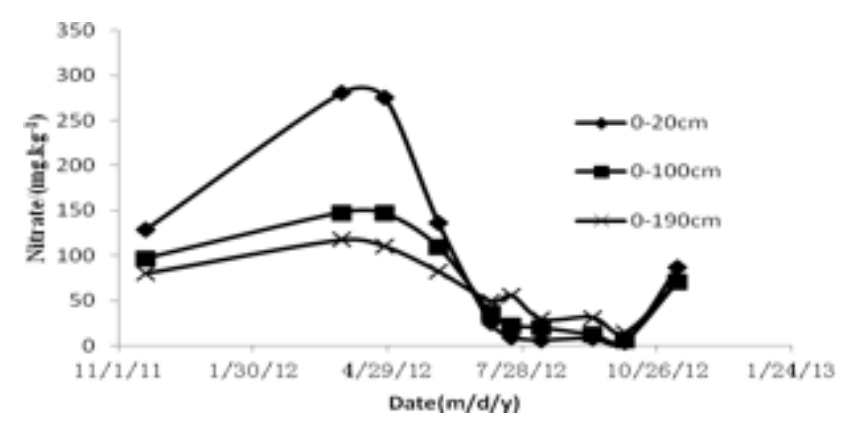

Fig. (4). Nitrate nitrogen dynamic changes in tilth soil. 


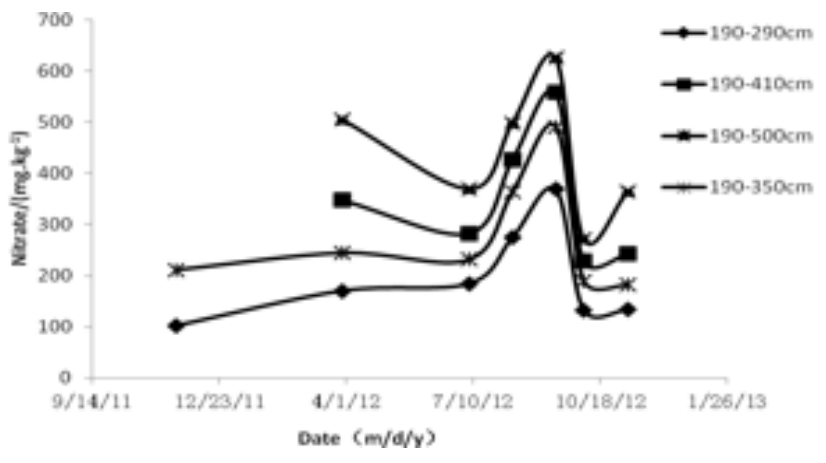

Fig. (5). Nitrate nitrogen dynamic changes in deep soil.

The crop root mainly exists in $0 \sim 180 \mathrm{~cm}$ soil layer in wheat-maize rotation area [20]. Combined with this experiment, the depth of plough layer is $0 \sim 190 \mathrm{~cm}$ in this paper. We can conclude that nitrate nitrogen content varies in sinusoidal curve at shallow tilth soil during the wheatmaize rotation period from Fig. (4). Nitrate content is $82.32 \sim 280.39 \mathrm{mg} / \mathrm{kg}$ in wheat growing period and maximum value is at green stage. Nitrate content is $3.42 \sim 65.08 \mathrm{mg} / \mathrm{kg}$ in maize growing period and minimum value is at harvest time. The trend of nitrate varieties is most evident in $0 \sim 20 \mathrm{~cm}$ soil layer, in turn, $0 \sim 100 \mathrm{~cm}$ and $0 \sim 190 \mathrm{~cm}$ soil layer. It is related to the local traditional cultivation and fertilization habits. When sowing wheat, base fertilizer is applied in farmland and nitrate content rise. However, nitrate consumption is less in seedling and wintering period. Most of nitrate is mainly accumulated in $0 \sim 100 \mathrm{~cm}$ soil and the maximum value occur at reviving stage. With the growth of wheat, nitrate content decreases in tilth soil. Fertilizer is applied in big flare period of the maize, which provides enough nutrients for maize growth. Due to absorption by maize and leaching by rainfall, nitrate content decreased rapidly in topsoil. In short, variation regularity of top soil nitrate content is sine curve under the traditional cropping pattern during the wheat- maize rotation.

\subsubsection{Distribution of Nitrate in Deep Soil}

Fig. (5) shows nitrate nitrogen content is in "W" shape at deep soil profile during the wheat-maize rotation period. Nitrate content changes slightly at deep soil profile in wheat growing period and it appears the shape of mountain peak in maize growing period. The peak of nitrate is at fillingmaturity stage. Precipitation is low in wheat growing period; top soil nitrate moves slightly downward by irrigation water and most nitrate mainly accumulates in tilth soil. Precipitation is $556.3 \mathrm{~mm}$ in maize growing period, which accounts for $80.5 \%$ of the annual precipitation. In rainy season, nitrate leaves the tilth soil and move downward deep soil by leaching of precipitation. The peak of nitrate is in mid-September. With the decrease of precipitation, nitrate content of the various deep soils reduces gradually and reaches the minimum in maize harvest time.

\subsubsection{Distribution of the Soil Nitrate in Rainy Season}

It can be concluded from Fig. (6) that the distribution of nitrate nitrogen is double peak curve in $0 \sim 500 \mathrm{~cm}$ soil profile.
The upper peak emerges at $40 \sim 100 \mathrm{~cm}$, and the value of nitrate content is between $26.7 \sim 54.6 \mathrm{mg} / \mathrm{kg}$. The lower peak appears at $150 \sim 260 \mathrm{~cm}$ and the peak of soil nitrate content are between $36.7 \sim 106.36 \mathrm{mg} / \mathrm{kg}$. The lower peak is higher than the upper and the two peaks move downward with the passage of time. Fertilization in maize growth period results in the upper peak of nitrate. The lower peak results from leaching of the residual nitrate in wheat growth period with irrigation and precipitation. The leaching process of the lower peak is shown in Fig. (3). The lower peak exists in $40 \sim 100 \mathrm{~cm}$ at wheat harvests. It moves respectively at $130 \sim 170 \mathrm{~cm}$ and $170 \sim 260 \mathrm{~cm}$ in the last ten-day period of July and middle ten days of September. The average migration rate is $1 \sim 2 \mathrm{~cm} / \mathrm{d}_{\text {。 }}$

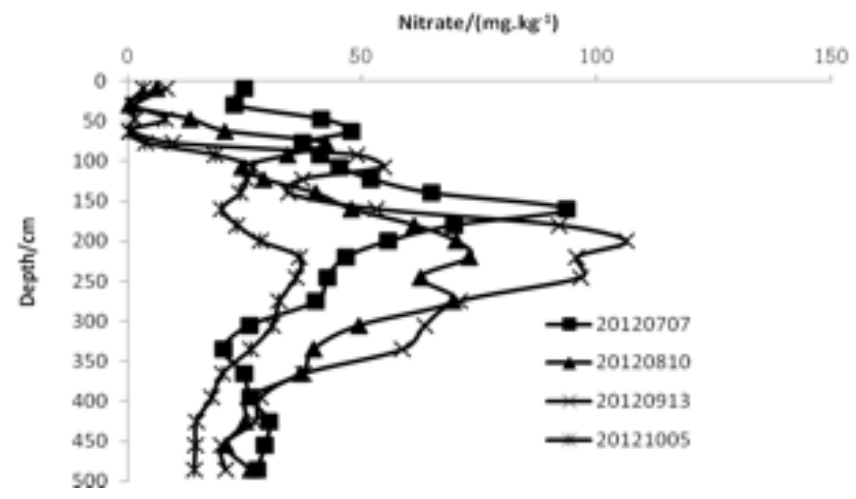

Fig. (6). Distribution of nitrate nitrogen in soil profile in rainy season.

\subsection{Accumulation and Nitrate Leaching in Soil}

Nitrate accumulation formula is as follows:

$N_{a c c}=0.1 \sum z \rho_{d} c$

where,

$N_{a c c}$--- the nitrate nitrogen accumulation, $\mathrm{kg} / \mathrm{hm}^{2}$;

$z$--- the depth of soil, $\mathrm{cm}$;

$\rho_{d}$---the soil bulk density, $\mathrm{g} / \mathrm{cm}^{3}$;

$c$---the soil nitrate content, $m g / k g$.

The calculation results are shown in Table $\mathbf{1}$.

In Table 1, the amount of nitrate nitrogen accumulation is $1878.86 \sim 3097.89 \mathrm{~kg} / \mathrm{hm}^{2}$ in the topsoil in the wheat growth period, which accounts for $57.08 \% \sim 60.43 \%$ in $0 \sim 500 \mathrm{~cm}$. It is $379.74 \sim 1343.74 \mathrm{~kg} / \mathrm{hm}^{2}$ in the topsoil in maize growth period, accounting for $26.54 \% \sim 48.82 \%$ in $0 \sim 500 \mathrm{~cm}$. Nitrate nitrogen below the topsoil cannot be absorbed by the crop and moves downward deep layer with irrigation and rainfall, as pollution source of the groundwater environment. Leaching amount of nitrate nitrogen is determined by calculating the difference between the maximum and the minimum of nitrate content below tilth layer during wheatmaize rotation cycle. The amount of nitrate nitrogen leaching is $1294.13 \mathrm{~kg} / \mathrm{hm}^{2}$, which is $52.29 \%$ of the total amount of annual fertilization. 
Table 1. Amount of accumulated nitrate nitrogen in different soil depth.

\begin{tabular}{|c|c|c|c|c|}
\hline \multirow{2}{*}{$\begin{array}{c}\text { Date } \\
(\mathbf{y}-\mathbf{m}-\mathbf{d})\end{array}$} & $\begin{array}{c}|c| \\
\text { 0ccumulation } \\
\left(\mathbf{k g} \cdot \mathbf{h m}^{-2}\right)\end{array}$ & $\begin{array}{c}\text { Percent } \\
\mathbf{( \% )}\end{array}$ & $\begin{array}{c}\text { Accumulation } \\
\left(\mathbf{k g} \cdot \mathbf{h m}^{-2}\right)\end{array}$ & $\begin{array}{c}\text { Percent } \\
(\%)\end{array}$ \\
\hline \hline 20111119 & 1405.59 & - & 2147.70 & - \\
\hline 20120329 & 2118.42 & 41.33 & 3097.89 & 60.43 \\
\hline 20120707 & 500.60 & 18.19 & 1343.74 & 48.82 \\
\hline 20120810 & 262.98 & 9.79 & 792.50 & 29.51 \\
\hline 20120913 & 161.47 & 5.04 & 856.63 & 26.76 \\
\hline 20121005 & 81.14 & 5.67 & 379.74 & 26.54 \\
\hline 20121109 & 985.92 & 29.95 & 1878.86 & 57.08 \\
\hline
\end{tabular}

\begin{tabular}{|c|c|c|c|c|}
\hline \multirow{2}{*}{$\begin{array}{c}\text { Date } \\
(\mathbf{y}-\mathbf{m}-\mathbf{d})\end{array}$} & $\begin{array}{c}\text { Accumulation } \\
\left.\mathbf{( k g} \cdot \mathbf{h m}^{-2}\right)\end{array}$ & $\begin{array}{c}\text { Percent } \\
(\%)\end{array}$ & $\begin{array}{c}\text { Accumulation } \\
\left(\mathbf{k g} \cdot \mathbf{h m}^{-2}\right)\end{array}$ & $\begin{array}{c}\text { Percent } \\
(\%)\end{array}$ \\
\hline \hline 20111119 & 2724.43 & - & - & - \\
\hline 20120329 & 3865.55 & 75.41 & 4464.05 & 87.09 \\
\hline 20120707 & 2086.67 & 75.81 & 2386.90 & 86.71 \\
\hline 20120810 & 1953.54 & 72.73 & 2382.34 & 88.70 \\
\hline 20120913 & 2392.11 & 74.72 & 2915.66 & 91.07 \\
\hline 20121005 & 977.82 & 68.35 & 1248.14 & 87.25 \\
\hline 20121109 & 2409.06 & 73.19 & 2780.65 & 84.48 \\
\hline
\end{tabular}

\begin{tabular}{|c|c|}
\hline \multirow{2}{*}{ Date (y-m-d) } & 0 500cm \\
\cline { 2 - 3 } & Accumulation $\left(\mathbf{k g} \cdot \mathbf{h m}^{-2}\right)$ \\
\hline \hline 20111119 & - \\
\hline 20120329 & 5126.05 \\
\hline 20120707 & 2752.64 \\
\hline 20120810 & 2685.88 \\
\hline 20120913 & 3201.58 \\
\hline 20121005 & 1430.56 \\
\hline 20121109 & 3291.39 \\
\hline
\end{tabular}

\section{CONCLUSION}

Field experiment was carried out and nitrate nitrogen was dynamic measured in wheat-maize growth period. Based on analysis of the experimental data, the temporal and spatial variation regularity of nitrate nitrogen was obtained in deep buried phreatic water. In general, nitrate nitrogen is mainly accumulated in $0 \sim 100 \mathrm{~cm}$ soil layer depth in wheat growth period. Nitrate nitrogen leaching is evident in $0 \sim 500 \mathrm{~cm}$ soil during maize growth period. The details are as follows:

1) The soil moisture varies from $21.23 \%$ to $41.67 \%$ in $0 \sim 500 \mathrm{~cm}$ soil layer. Two peak zones occur respectively at $40 \sim 100 \mathrm{~cm}$ and $300 \sim 400 \mathrm{~cm}$ in soil profile and the maximum value are $36.59 \%$ and $41.67 \%$. The lower peak zone results from excessive irrigation water and precipitation infiltration. Soil moisture nears to field capacity between two peak zones and tends to be stable below $400 \mathrm{~cm}$ soil layer.

2) Nitrate nitrogen content varies in sinusoidal curve at shallow tilth soil and shows in "W" shape at deep soil profile during the wheat-maize rotation period. Nitrate nitrogen is mainly accumulated in $0 \sim 100 \mathrm{~cm}$ soil. In the maize growth period, the distribution of nitrate nitrogen is double peak curve in $0 \sim 500 \mathrm{~cm}$ soil profile, The upper peak emerges at $40 \sim 100 \mathrm{~cm}$, and the value of nitrate content is $26.7 \sim 54.6 \mathrm{mg} / \mathrm{kg}$. The lower peak appears at $150 \sim 260 \mathrm{~cm}$ and the value of soil nitrate content is $36.7 \sim 106.36 \mathrm{mg} / \mathrm{kg}$.

3) In $0 \sim 500 \mathrm{~cm}$ soil layers, the amount of nitrate nitrogen accumulation is $1430.56 \sim 5126.05 \mathrm{~kg} / \mathrm{hm}^{2}$. It is evident that nitrate nitrogen moves downward during maize growth period. The amount of nitrate nitrogen leaching is $1294.13 \mathrm{~kg} / \mathrm{hm}^{2}$, which is $52.29 \%$ of the total amount of annual fertilization.

\section{CONFLICT OF INTEREST}

The authors confirm that this article content has no conflict of interest.

\section{ACKNOWLEDGEMENTS}

This work was financially supported by Natural Science Fund of Hebei province (E2015204205) and Hebei Province Science \& Technology department (15963608D).

\section{REFERENCES}

[1] Y.M. Zhang, C.S. Hu and J.B. Zhang Jiabao, "Nitrogen cycling and balance in agricultural ecosystem in piedmont plain of Taihang Mountains", Plant Nutrition and Fertilizer Science, vol. 12, no. 1, pp. 5-11, 2006.

[2] G.H. Zhang, Z.P. Liu and Y.L. Lian, "Variation of Groundwater Quality and Influence of Pesticide and Fertilizer on Hebei Plain", South-to-North Water Transfers and Water Science \& Technology, vol.7, no. 2, pp. 50-54, 2009.

[3] Y.D. Fang, Z.M. Feng and Y.C. Hu, "Balance of field nitrogen nutrient input/output using GIS technology in China", Transactions of the Chinese Society of Agricultural Engineering, vol.23, no.7, pp. 35-41, 2007.

[4] J. Aleksandra, Z. Zeljka and S. Ivana, "Nitrate-Nitrogen Content in Soil and Lysimeter Water under Different Nitrogen Fertilization Levels in Crop Production", Agricultural Conspectus Scientificus (ACS), vol.79, no.1, pp. 45-50, 2014.

[5] H. Jan and K. Martin, "Simulation of nitrogen leaching and nitrate concentration in a long-term field experiment", Journal of Central European Agriculture, vol.13, no.3, pp. 416-425, 2012.

[6] A. Amaya, A.M. Ian and K.P. Chandra, "Nitrogen Dynamics and Nutrient Budgets in Four Orchard Groundcover Management Systems", HORTSCIENCE, vol.46, no.8, pp. 1184-1193, 2011.

[7] J. A. de Vos, D. Hesterberg and P. A. C. Raats, "Nitrate Leaching in a Tile-Drained Silt Loam Soil", Soil Science Society of America Journal, vol.46, pp. 517-527, 2000. 
[8] C. Enio, M. Roberto and R. Emanuele, "Legume cover crops and mulches: effects on nitrate leaching and nitrogen input in a pepper crop", Nutrient Cycling in Agroecosystems, vol.89, pp. 399-412, 2011.

[9] J.H. Ma and L.Ren, "Numerical simulation on nitrate leaching at field scale during the growth of winter wheat", Acta Ecologica Sinica, vol.24, no.10, pp. 2289-2301, 2004.

[10] L.Ren, F.S.Yuan and F.S. Zhang, "Simulation and prediction of nitrate-nitrogen leaching from soils under the growth period of winter wheat using transfer function model", Acta Ecologica Sinica, vol.24, no.10, pp. 2281-2288, 2004.

[11] Y.G. Zhao and M.G. Shao, "Experimental Study on Nitrate Transport for Different Fertilization Methods", Transactions of the Chinese Society of Agricultural Engineering, vol.18, no.4, pp. 3740, 2002.

[12] T.H. Dang, S.L. Guo and J. Fan, "NO ${ }^{3-}-\mathrm{N}$ leaching and distribution in soil profile in dry highland of Loess Plateau under long-term fertilization", Chinese Journal of Applied Ecology, vol.14, no.8, pp. 1265-1268, 2003.

[13] S.Y. Feng, Y.F. Zhang and R.K. Sheng, "Experimental study and numerical modeling of nitrogen transport and transformation in unsaturated soils", Journal of Hydraulic Engineering, no.8, pp. 815, 1996.

[14] X.X. Li, C.S. Hu, Y.M. Zhang, etc., "Losses of nitrate nitrogen from a wheat-Corn rotation in north China", Agricultural Research in the Arid Areas, vol.24, no.6, pp. 7-10, 2006.
[15] M.H. Dai, H.B. Tao and L.N. Wang, "Characteristics of Soil $\mathrm{NO}^{3-}$ $\mathrm{N}$ Changing and Nitrogen Mineralization During Spring Maize Seasons in the North China Plain", Journal of Soil and Water Conservation, vol.22, no.3, pp. 76-81, 2008.

[16] Z.L. Shi, S.J. Yang and C.H. Zhang, "Effect of Nitrogen Application on Soil Nitrate Nitrogen Content, Root Growth and Nitrogen Utilization of Winter Wheat in Rice-Wheat Rotation", Journal of Soil and Water Conservation, vol.26, no.5, pp. 118-122, 2011.

[17] Y.H. Kang, Y.G. Ma and Q.H. Wang, " $\mathrm{NO}^{3-}-\mathrm{N}$ deep migration in loess layer of non-saturated zone under irrigation condition", Agricultural Research in the Arid Areas, vol.24, no.6, pp.147-150, 2006.

[18] C.S. Hu, W.X. Dong and Y.M. Zhang, "Nitrogen flux and its manipulation in the cropland ecosystem of the North China Plain", Chinese Journal of Eco-Agriculture, vol.19, no.5, pp.997-1003, 2011.

[19] F.Z. Shang, P.L. Yang and Y.K. Li, etc., "Effects of different chemical nitrogenous fertilizer application rates on soil nitrogen leaching and accumulation in deep vadose zone", Transactions of the Chinese Society of Agricultural Engineering, vol.28, no.7, pp.103-110, 2012.

[20] X.Y. Zhang, Crop root and utilization of soil water, CA: Beijing, 2012.

\section{(C) Gao and Yang; Licensee Bentham Open.}

This is an open access article licensed under the terms of the Creative Commons Attribution Non-Commercial License (http://creativecommons.org/licenses/by$\mathrm{nc} / 3.0 /$ ) which permits unrestricted, non-commercial use, distribution and reproduction in any medium, provided the work is properly cited. 